\title{
EVALUATION OF SPORULATION MEDIA FOR YEASTS OBTAINED FROM PATHOLOGICAL MATERIAL
}

\author{
A. E. Merritt and Rosalinde Hurley \\ Queen Charlotte's Maternity Hospital and the Institute of Obstetrics and \\ Gynaecology, University of London
}

SPORULATION is fundamental to the classification of yeasts since it distinguishes the perfect from the imperfect genera. However, it is often difficult to induce in practice, and, consequently, it does not always figure in schemes of identification, where pairs of perfect and imperfect forms may be adjudged identical on physiological and growth characteristics (Beech et al., 1968). The distinction based on sporulation is one of practical importance in medical mycology, for some imperfect yeasts, such as many species of Candida (Hurley, 1967), are pathogenic for man and animals, whereas perfect yeasts, such as Saccharomyces or Hansenula, are not, save in the most exceptional circumstances. The demonstration of ascospores in yeasts isolated from superficial sites in man is significant, for it allows the pathologist to assign the isolate to a non-pathogenic genus.

Studies are often undertaken to ascertain the perfect (fruiting) forms of imperfect fungi of pathological importance, partly to clarify their taxonomic position, and partly to render them more amenable to genetical analysis. Successful studies have been made on dermatophytes (Ajello, 1971) and Candida species have also been investigated. Some perfect forms of candidas were discovered through physiological relationships (Diddens and Lodder, 1939), others through studies of molecular biology (Stenderup and Leth Bak, 1968), and others through mating experiments (Wickerham and Burton, 1954).

Since mating studies in Candida and related species depend finally upon the demonstration of fruiting bodies, and since some isolates encountered in routine clinical practice may be assigned to the wrong genus if simple and reliable media for the demonstration of sporulation are not available, we have made a comparative study of three solid media commonly recommended for demonstration of ascospores, using as our test organisms diploid lines of Saccharomyces cerevisiae of unremarkable sporing quality, and two haploid mating strains of Hansenula anomala (Candida pelliculosa).

The purpose of this paper is to evaluate sodium acetate, Gorodkowa and V8 sporulation agar as media for demonstration of ascospores in clonally related, single-cell cultures derived from vegetative cells and from ascospores.

\section{MATERIALS AND METHODS}

Organisms. Three laboratory isolates of Saccharomyces cerevisiae, originating from man and satisfying the criteria of identification of Lodder (1970), were used. They were designated strains 1,2 and 3; strain 1 was singled out for special study. Hansenula anomala strains

Received 15 January 1971; accepted 15 June 1971.

J. MED. MICROBIOL.-VOL. 5 (1972) 
433 and 435 were obtained from the Brewing Industry Research Foundation. They satisfied the physiological criteria of identification for $H$. anomala, but as they were asporogenous in unmixed culture, we assigned them to C. pelliculosa following Lodder and Kreger-Van Rij (1952).

Pre-sporulation conditions. The yeasts were cultured on glucose-peptone agar of the formula: glucose $40 \mathrm{~g}$, peptone $10 \mathrm{~g}$, Oxoid ionagar $15 \mathrm{~g}$ and distilled water $1000 \mathrm{ml}$, poured in sterile petri dishes. The cultures were grown in three successive $24-\mathrm{hr}$ subcultures incubated at $30^{\circ} \mathrm{C}$.

Sporulation conditions. Three solid sporulation media were examined.

1. Sodium acetate agar: $\mathrm{CH}_{3} \mathrm{COONa} .3 \mathrm{H}_{2} \mathrm{O} 10 \mathrm{~g}$, glucose $1 \mathrm{~g}$, Oxoid Yeast Extract Powder $2.5 \mathrm{~g}$, Oxoid ionagar $20 \mathrm{~g}$ and distilled water $1000 \mathrm{ml}$.

2. Gorodkowa agar: $\mathrm{NaCl} 5 \mathrm{~g}$, glucose $1 \mathrm{~g}$, Oxoid Mycological Peptone $10 \mathrm{~g}$, Oxoid ionagar $30 \mathrm{~g}$ and distilled water $1000 \mathrm{ml}$.

3. V8 agar: V8 juice (commercial vegetable juice) $500 \mathrm{ml}$, Oxoid ionagar $20 \mathrm{~g}$ and distilled water $500 \mathrm{ml}$.

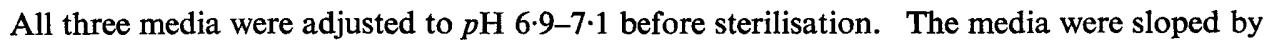
pouring $5 \mathrm{ml}$ into $20-\mathrm{ml} \mathrm{McCartney}$ bottles on the day they were to be used, and the slopes were inoculated with sufficient cells to produce a continuous growth across the agar surface.

Single cell and ascospore cultures. Single cells were obtained from each of the strains with a de Fonbrune micromanipulator, and isolated cells were incubated on glucose-peptone agar at $30^{\circ} \mathrm{C}$. Fifteen subcultures, deriving from a clone produced from a single cell, were examined from each of the three strains of $S$. cerevisiae and 12 subcultures were examined from mixtures of the strains of $\boldsymbol{H}$. anomala. The subcultures were grown on Gorodkowa, sodium acetate and V8 medium at two temperatures of incubation $\left(23^{\circ} \mathrm{C}\right.$ and $\left.30^{\circ} \mathrm{C}\right)$. Thus, in this part of the experiment, 342 sporulation slopes were inoculated.

In addition, 12 single ascospore and 12 single-cell cultures from the homothallic strain 1 of $S$. cerevisiae were examined. Ascospore cultures were obtained by suspending micromanipulated asci in 10 per cent. snail-juice digestive enzyme (Industrie Biologique Française) for $2-3 \mathrm{hr}$ at $30^{\circ} \mathrm{C}$. After this time, the ascus walls were sufficiently softened to enable the spores to be separated by manipulation with a microloop. The ascospores were incubated on glucose-peptone agar at $30^{\circ} \mathrm{C}$, and cells from the $48-\mathrm{hr}$ clone were subcultured. The 12 cultures derived from single vegetative cells, and the 12 derived from ascospores were inoculated on Gorodkowa and sodium acetate agar at two temperatures of incubation $\left(23^{\circ} \mathrm{C}\right.$ and $30^{\circ} \mathrm{C}$ ). Thus, 48 sporulation slopes were inoculated.

S. cerevisiae sporulation slopes were examined at 4, 7, 11, 20, 25 and 32 days after inoculation, and smears were stained for asci. H. anomala sporulation slopes were examined at 3 , $10,14,25,32$ and 39 days.

Staining of ascospores. Heat-fixed smears were stained with near-boiling 2.5 per cent. malachite green for $2 \mathrm{~min}$. The slides were thoroughly washed with tap water and counterstained with 0.5 per cent. safranin for $1 \mathrm{~min}$., followed by a thorough wash with tap water. The number of asci present was estimated by counting at least 600 structures and structures containing green-stained bodies were classed as asci. When very few asci were present, 2000-3000 structures were examined. If more than 1 per cent. of the structures counted were asci, we refer to this as an "appreciable number".

\section{RESULTS}

\section{Saccharomyces cerevisiae}

The mean results for ascospore production for all three strains are shown in fig. 1. Asci developed more quickly at $23^{\circ} \mathrm{C}$ than at $30^{\circ} \mathrm{C}$. On sodium acetate medium all cultures contained ascospores, at both temperatures, after 25 days. On Gorodkowa medium incubated at $23^{\circ} \mathrm{C}$ all but 2 of the 45 cultures 
contained asci after 25 days, but asci were detected in only a quarter of the cultures incubated at $30^{\circ} \mathrm{C}$. With both media, at each of the temperatures, development of asci was rapid and the majority of the cultures contained asci after 11 days. On the V8 medium sporulation was low, and the yield at the more favourable temperature $\left(23^{\circ} \mathrm{C}\right)$ was no better than the yield on Gorodkowa agar at $30^{\circ} \mathrm{C}$. At $30^{\circ} \mathrm{C}$ asci were seen in only 1 of 45 cultures examined. Prolongation of the incubation time up to 62 days did not improve sporulation.

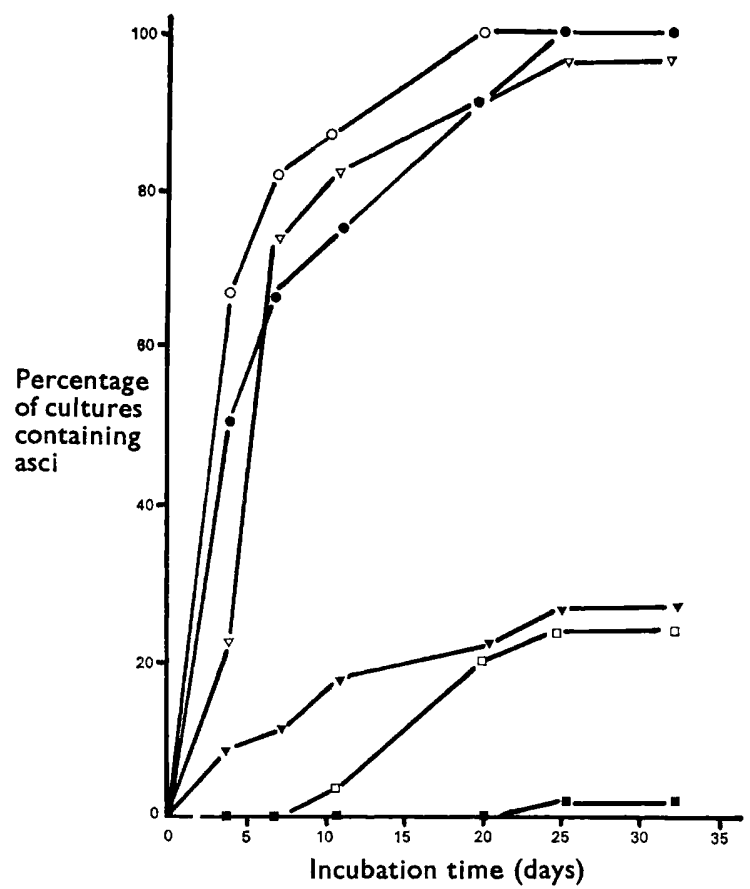

FIG. 1.-The effect of sporulation medium and incubation temperature on the percentage of cultures of Saccharomyces cerevisiae containing asci. O Sodium acetate medium incubated at $23^{\circ} \mathrm{C}$; - sodium acetate medium incubated at $30^{\circ} \mathrm{C} ; \nabla$ Gorodkowa medium incubated at $23^{\circ} \mathrm{C}$; $\nabla$ Gorodkowa medium incubated at $30^{\circ} \mathrm{C} ; \square \mathrm{V} 8$ medium incubated at $23^{\circ} \mathrm{C}$; V8 medium incubated at $30^{\circ} \mathrm{C}$.

Figure 2 shows the mean result for the three strains after 32 days. Although sporulation was reduced on sodium acetate medium at the higher temperature, an appreciable number of asci was produced in most cultures. The proportion of poorly sporing cultures was higher on Gorodkowa medium than on sodium acetate medium, and cultures incubated on Gorodkowa medium at $23^{\circ} \mathrm{C}$ contained very few asci; sporing cultures contained just over 1 per cent. Many cultures contained no ascospores at $30^{\circ} \mathrm{C}$ and the percentage yield of asci was reduced. The development of asci on V8 medium was slow and poor; they were few in number and did not reach an appreciable number in any of the cultures even after 62 days.

The results with strain 1 are shown in fig. 3. Ascospores were produced most abundantly on sodium acetate medium at $23^{\circ} \mathrm{C}$ and least on Gorodkowa 


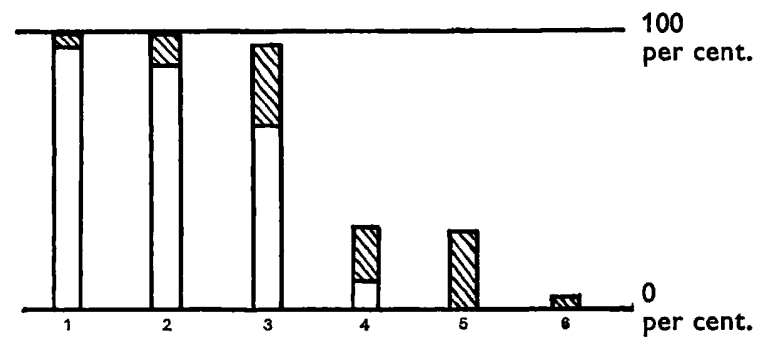

FIG. 2.-The development of asci in cultures of Saccharomyces cerevisiae after incubation for 32 days. Asci present but not in appreciable numbers $(<1$ per cent.); $\square$ asci present in appreciable number $\left(>1\right.$ per cent.). (1) Sodium acetate medium incubated at $23^{\circ} \mathrm{C} ;$ (2) sodium acetate medium incubated at $30^{\circ} \mathrm{C}$; (3) Gorodkowa medium incubated at $23^{\circ} \mathrm{C}$; (4) Gorodkowa medium incubated at $30^{\circ} \mathrm{C}$; (5) V8 medium incubated at $23^{\circ} \mathrm{C}$; (6) V8 medium incubated at $30^{\circ} \mathrm{C}$.

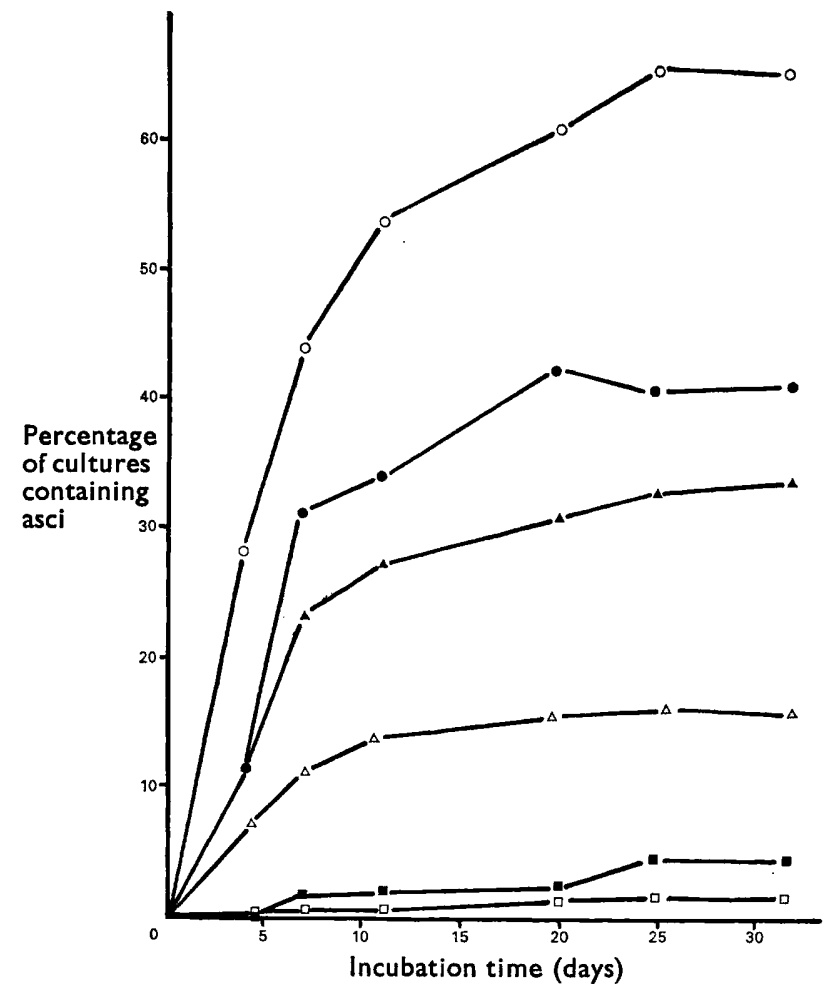

FIG. 3.-The effect of sporulation medium and incubation temperature on the percentage of asci produced in ascospore cultures and cell cultures of a homothallic strain of Saccharomyces cerevisiae. O Sodium acetate medium incubated at $23^{\circ} \mathrm{C}$ for ascospore cultures; $\triangle$ sodium acetate medium incubated at $30^{\circ} \mathrm{C}$ for ascospore cultures; $\square$ Gorodkowa medium incubated at $23^{\circ} \mathrm{C}$ for ascospore cultures; - sodium acetate medium incubated at $23^{\circ} \mathrm{C}$ for cell cultures; $\Delta$ sodium acetate medium incubated at $30^{\circ} \mathrm{C}$ for cell cultures; Gorodkowa medium incubated at $23^{\circ} \mathrm{C}$ for cell cultures. 
medium, for both cell- and ascospore-derived cultures. The effect of temperature was more marked with the ascospore-derived cultures.

\section{Hansenula anomala}

The strains studied could not be induced to produce ascospores when streaked separately on V8 or other sporulation media and incubated at $23^{\circ} \mathrm{C}$. However, when a mixture of the two was streaked on V8 medium, and treated in the same manner, there was a high yield of asci. Thus, the isolates appeared to be stable heterozygous haploid strains of opposite mating type; conjugation was frequently observed in the mixed cultures, and was noticed before sporulation was observed and during the period when the percentage of asci in the culture was still rising.

Single cells were isolated from cultures of the two strains, and of mixtures, with a de Fonbrune micromanipulator. A range of sizes of cells was isolated and the single cell cultures were grown on glucose-peptone agar. None of the cultures derived from single cells produced ascospores when cultured alone on V8 medium; they consisted of mating haploids, which produced ascospores only when mixed with one or other of the original strains, or else they were non-sporing, non-mating cultures.

The sporulation experiments were, therefore, performed on mixtures of strains 433 and 435 . The strains were cultured separately in the presporulation period. Equal quantities of the two strains were then intimately mixed in a little sterile distilled water before they were streaked on slopes of sporulation media.

Initially, the number of structures counted as asci included only those that contained blue-green-staining ascospores. However, a considerable number of structures resembling asci were observed, the hat-shaped spores of which stained red, not blue-greeen. As Phaff and Mrak (1948) have reviewed several reports of yeasts producing ascospores that do not stain differentially by the standard techniques, these structures were also counted as asci. They proved easy to distinguish from the vegetative cells, as the hat-shaped spores were distinctive and stained more palely red with safranin than did the vegetative cells. The results were based on the total ascus count irrespective of whether the spores stained red or blue-green. In many cases smears were stained only with safranin.

The outer walls of asci were rather fragile and often ruptured to release the spores, a characteristic noted by Bedford (1941), but in most cases the ascospores adhered together and could be counted with some confidence as arising from one ascus. In some cases the ascospores from a single ascus separated: for example, four ascospores may have split into two pairs. Where this occurred, the derivative ascus count may have erred on the high side. However, we consider that the proportionate overestimation of the number of asci is likely to be similar with all the cultures, since the disruption of asci was not related to the sporulation medium used and occurred on all the media.

Figure 4 shows that ascospores developed in all cultures after 3 days' 
incubation at $23^{\circ} \mathrm{C}$ on sodium acetate medium. Incubation at $30^{\circ} \mathrm{C}$ caused delay in ascus formation, but all cultures contained asci after 25 days. On V8 medium, asci were demonstrable in the majority of cultures after incubation for

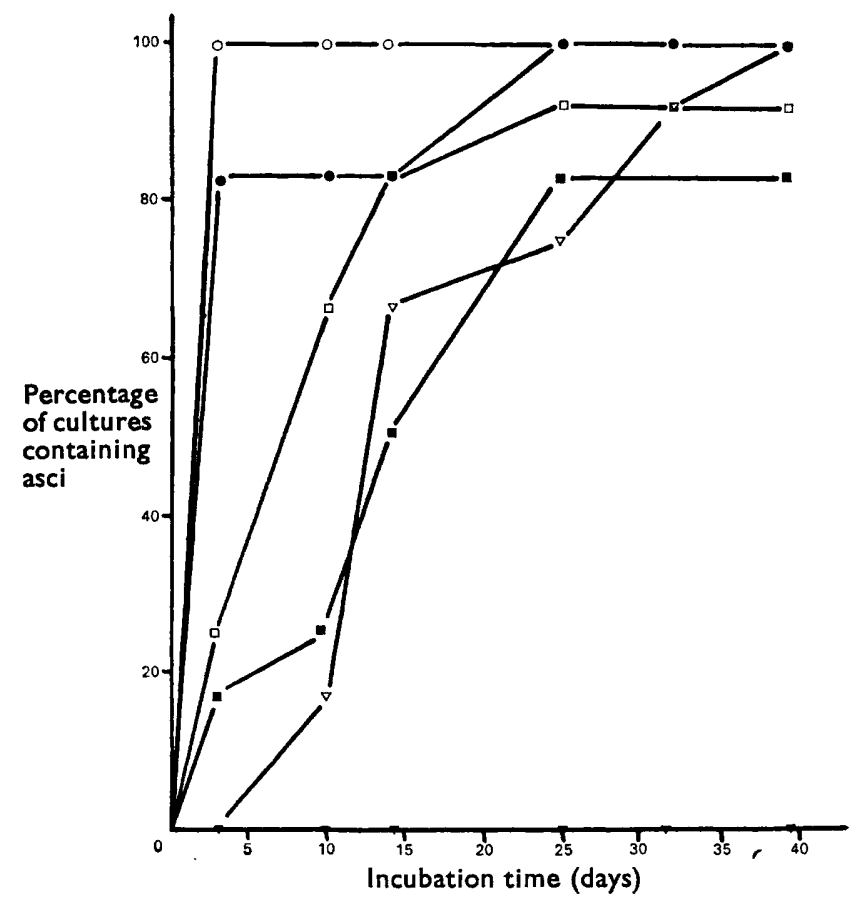

FIG. 4.-The effect of sporulation medium and incubation temperature on the percentage of cultures of Hansenula anomala containing asci. O Sodium acetate medium incubated at $23^{\circ} \mathrm{C}$; $\bullet$ sodium acetate medium incubated at $30^{\circ} \mathrm{C} ; \nabla$ Gorodkowa medium incubated at $23^{\circ} \mathrm{C} ; \nabla$ Gorodkowa medium incubated at $30^{\circ} \mathrm{C}$; $\square \mathrm{V8}$ medium incubated at $23^{\circ} \mathrm{C}$; V8 medium incubated at $30^{\circ} \mathrm{C}$.

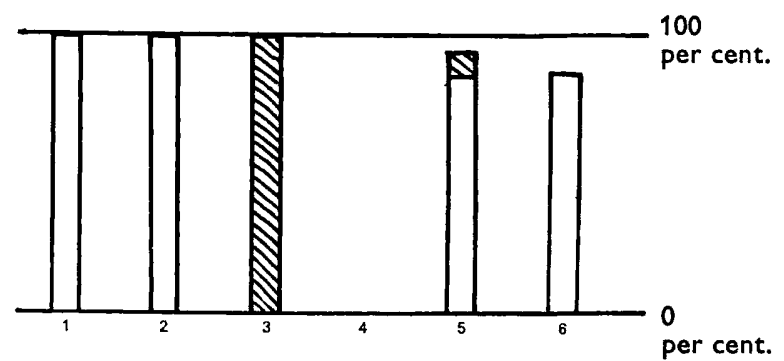

FIG. 5.-The development of asci in cultures of Hansenula anomala after incubation for 39 days. Asci present but not in appreciable numbers $(<1$ per cent.); $\square$ asci present in appreciable number $\left(>1\right.$ per cent.). (1) Sodium acetate medium incubated at $23^{\circ} \mathrm{C}$; (2) sodium acetate medium incubated at $30^{\circ} \mathrm{C}$; (3) Gorodkowa medium incubated at $23^{\circ} \mathrm{C}$; (4) Gorodkowa medium incubated at $30^{\circ} \mathrm{C}$; (5) $\mathrm{V} 8$ medium incubated at $23^{\circ} \mathrm{C}$; (6) $\mathrm{V} 8$ medium incubated at $30^{\circ} \mathrm{C}$.

25 days, but a few cultures contained no asci at $23^{\circ} \mathrm{C}$, and at $30^{\circ} \mathrm{C}$ even more were asporogenous. The effect of temperature on sporulation was similar, but more marked on Gorodkowa medium. After 39 days, all the cultures incubated at $23^{\circ} \mathrm{C}$ contained asci, whilst none of those incubated at $30^{\circ} \mathrm{C}$ had spored. 
The progress curve of the development of asci in the cultures incubated at $23^{\circ} \mathrm{C}$ was irregular compared with the other curves (fig. 4) which were regular and reached a maximum after 25 days' incubation. Figure 5 shows that although all the cultures incubated on Gorodkowa medium at $23^{\circ} \mathrm{C}$ contained a small proportion of asci, none contained more than 1 per cent. This is in marked contrast with the results obtained with the other two media, where the majority of the cultures showed either no asci or an appreciable number ( $>1$ per cent.).

\section{Discussion}

Precultural conditions are important in the sporulation of yeasts (Phaff and Mrak, 1948), but the most significant factor appears to be that the culture should be composed of young vigorous cells. In the experiments reported here, young cultures were obtained by three successive 24-hr subcultures in the presporulation phase. Overnight cultures on glucose-peptone agar are suitable for fresh isolates in the routine diagnostic laboratory.

The three media chosen for study are among the most common of those agar-solidified sporulation media that have been recommended and used for several years, although formulations vary. The results show that the choice of medium and the temperature of incubation profoundly influence the rapidity of development, and the percentage yield of ascospores.

None of the single-cell cultures obtained from H. anomala strain 433 and 435 produced ascospores when streaked separately on sporulation media. Thus, as asporogenous yeasts, they complied with the criteria of identification of Candida pelliculosa (Lodder and Kreger-van Rij, 1952), which is regarded as the imperfect stage of $H$. anomala. These species have identical physiological characteristics, and differ only in their ability to form fruiting bodies. Conjugation and ascus formation were observed when the isolates were mixed (i.e., mated), and they were demonstrated as stable haploid mating strains of $H$. anomala of opposite type. Wickerham and Burton (1954) observed that some yeasts classified in asporogenous genera are haploid mating types; they mated strains of $C$. pelliculosa and demonstrated the typical hat-shaped spores of Hansenula. It is common practice to test yeast isolates for sporulation singly, as though all were homothallic; under such conditions, heterothallic haploids, which do not self-diploidise, will be placed in supposedly nonascosporogenous genera, such as Candida (Wickerham and Burton, 1960). In our own laboratory, isolates of human origin tentatively classified as Candida species have proved to be haploid mating strains of perfect fungi after simple mating studies (Bailey and Hurley, unpublished).

Sporulation was depressed on all the sporulation media at the higher temperature, and it was achieved more quickly or to a greater extent at $23^{\circ} \mathrm{C}$ than at $30^{\circ} \mathrm{C}$. Poor sporulation at $30^{\circ} \mathrm{C}$ was noticeable even though the presporulation temperature was $30^{\circ} \mathrm{C}$, although Stantial (1928) found that the yield of asci at a particular sporulation temperature was greater when the sporulation and presporulation temperatures were the same.

Sodium acetate medium allowed optimum sporulation. Roth (1970) showed that carbohydrates, mainly in the form of trehalose, accumulate in 
yeast cells after the cessation of vegetative reproduction, and before the appearance of ascus walls. His experiments were carried out in liquid media lacking assimilable nitrogen and asci were obtained quickly. The solid medium approximating most closely to the formulation of Roth's medium is the sodium acetate medium, which is low in assimilable nitrogen and richer in carbohydrate than either Gorodkowa or V8 medium. Lack of nitrogen is probably the factor that limits vegetative growth, and a high carbohydrate content allows that accumulation of trehalose that is preliminary to ascospore production.

With solid sporulation media some initial vegetative growth is almost essential because of the comparatively small inoculum used for routine purposes, and there is a corresponding lag period before the initiation of ascospore production. Roth, and Esposito and Esposito (1969), who used large inocula in liquid media containing no assimilable nitrogen, obtained asci quickly. The lag before the appearance of asci was more prolonged and vegetative growth was greater on Gorodkowa and V8 media, which contain more assimilable nitrogen and less carbohydrate than sodium acetate medium. Under all experimental conditions there was a correlation between the quantity of initial growth and the time of appearance and percentage yield of asci. Sodium acetate medium showed least vegetative growth and the most rapid production and the highest percentage of asci; V8 medium, and to a lesser extent Gorodkowa medium, allowed more vegetative growth but a lower yield of asci. The inverse relationship between vegetative growth and ascospore production has been previously observed by several workers, including Hansen (1902). H. anomala gave a higher yield of asci on V8 agar than on Gorodkowa medium, and V8 medium seems to be particularly suited to its sporulation. V8 contains carrot juice, and Bedford (1941) found carrot wedges very efficient for inducing sporulation in Hansenula species. Barker (1902) showed that $H$. anomala formed no asci on gypsum blocks unless nutrients were added; in contrast, $S$. cerevisiae formed asci in the absence of nutrients, and fewer asci if nutrients were added. Thus V8 medium may be too rich in nutrients to favour sporulation in $S$. cerevisiae, and not all our cultures of $H$. anomala would spore on it. Therefore, we prefer sodium acetate medium for both species.

Gorodkowa medium was moderately useful for inducing sporulation in $S$. cerevisiae, but was of little value for $H$. anomala, and in none of the cultures was an appreciable number of asci formed. Even the feeble ascospore formation apparent at the favourable temperature of $23^{\circ} \mathrm{C}$ was absent at $30^{\circ} \mathrm{C}$. We ascribed this clear-cut temperature effect to the basic inability of the medium to induce more than minimal sporulation in $H$. anomala.

The sporulation characteristics of the ascospore-derived cultures from the homothallic strain of $S$. cerevisiae were similar to those of cell cultures from the same strain, but the effect of environment was more marked. In the most favourable conditions the ascospore cultures contained more asci than the cell cultures, but as the conditions of temperature and medium became unfavourable the situation was reversed. Thus, ascospore cultures were much more sensitive to sporulation conditions than were the cell cultures, but sodium acetate medium was again the best choice. 
Much experimental work on the sporulation characteristics of yeasts has been performed on strains chosen for their free sporing characteristics (Roth and Halvorson, 1969). However, in diagnostic laboratories identification is often required of yeasts that do not spore freely, and probably require an environment close to their ideal sporulation conditions before they will produce any ascospores at all. For this reason, we chose for our experiments isolates having no special sporulation characteristics, such as may be encountered in routine diagnostic laboratories. Our results show that the choice of sporulation medium and its incubation temperature are critical for the demonstration of ascospores in $S$. cerevisiae and $H$. anomala. Best results are obtained with sodium acetate medium incubated at a low temperature. We are unable to recommend V8 sporulation medium as the medium of choice even for Hansenula species in view of the failure of some of our subcultures to sporulate on it. V8 medium must vary from batch to batch, since it is not chemically defined, and it may be unreliable for that reason. We find no evidence that use of all three media improves the chances of demonstrating ascospores, since all our cultures for the type species of Saccharomyces and Hansenula sporulated on sodium acetate agar.

Yeasts having the physiological characteristics of perfect yeasts have sometimes been placed erroneously in the pathogenic genus Candida because the production of ascospores could not be demonstrated. With sodium acetate medium the procedure outlined here is simple and reliable, and is well within the competence of diagnostic laboratories. We recommend that sporulation studies be made on yeasts from pathological material that cannot be identified readily as to species. Yeasts that do not spore in unmixed culture may do so on mating, and mating studies should be made if doubt persists about generic identification.

\section{SUMMARY}

Non-pathogenic perfect yeasts isolated from clinical material are sometimes erroneously identified as species of imperfect genera, such as Candida, because sporulation studies have not been made. Such misidentified isolates may be regarded as pathogens.

The sporulation characteristics of two haploid mating strains of Hansenula anomala and three homothallic strains of Saccharomyces cerevisiae of indifferent sporing quality were examined, by comparing clonally related isolates derived from single vegetative cells, or from ascospores. The haploid strains produced spores only after mating. The media tested were sodium acetate agar, Gorodkowa agar, and V8 agar, and two temperatures of incubation, $23^{\circ} \mathrm{C}$ and $30^{\circ} \mathrm{C}$, were used.

All subcultures of $S$. cerevisiae spored within 25 days on sodium acetate agar, and sporing occurred more rapidly at $23^{\circ} \mathrm{C} ; 67$ per cent. spored at 5 days. Subcultures of $H$. anomala spored within 3 days. This medium is therefore recommended for use in diagnostic laboratories in the investigation of yeast isolates that cannot be identified readily as to genus or species. 


\section{REFERENCES}

AJELLO, L. 1971. Sexual reproduction among fungi pathogenic to man, an historical review. Proc. X Int. Congr. Microbiol., Mexico, 1970, in press.

BARKER, B. T. P. 1902. On spore-formation among the Saccharomycetes. J. Inst. Brew., $8,26$.

BEDFORD, C. L. 1941. The genus Hansenula Sydow, morphological and physiological studies. Thesis, Univ. California.

Beech, F. W., Davenport, R. R., Goswell, R. W., and Burnett, J. I. 1968. Two simplified schemes for identifying yeast cultures. In Identification methods for microbiologists, ed. by B. M. Gibbs and D. A. Shapton, London and New York, pt B, pp. 151-175.

DidDens, H. A., AND LODDER, J. 1939. On some sporogenous yeasts and their imperfect stages. Mycopath. Mycol. appl., 2, 28.

ESPOSITO, M. S., AND EsPosito, Rochille E. 1969. The genetic control of sporulation in Saccharomyces. 1. The isolation of temperature-sensitive sporulation-deficient mutants. Genetics, Princeton, 61, 79.

HANSEN, E. C. 1902. Recherches sur la physiologie et la morphologie des ferments alcooliques. XII. C. r. Trav. Lab. Carlsberg, 5, 68.

HuRley, Rosalinde 1967. The pathogenic candida species: a review. Rev. Med. Vet. Mycol., 6, 159.

LODDER, J. 1970. The yeasts, a taxonomic study, 2nd ed., Amsterdam.

LODDER, J., AND KreGER-VAN RIJ, N. J. W. 1952. The yeasts, a taxonomic study, ed. by J. Lodder, Amsterdam.

Phaff, H. J., AND MraK, E. M. 1948. Sporulation in yeasts, pt 1. Wallerstein Labs Commun., 11, 261.

Roth, R. 1970. Carbohydrate accumulation during the sporulation of yeast. J. Bact., 101, 53.

Roth, R., AND Halvorson, H. O. 1969. Sporulation of yeast harvested during logarithmic growth. J. Bact., 98831.

Stantial, Helen 1928. The sporulation of yeast. Trans. Roy. Soc. Canad., sect. III, 22, 257.

Stenderup, A., AND Leth BaK, A. 1968. Deoxyribonucleic acid base composition in some species within the genus Candida. J. Gen. Microbiol., 52, 231.

WICKeRHAM, L. J., AND BURTON, K. A. 1954. A clarification of the relationship of Candida guilliermondii to other yeasts by a study of their mating types. J. Bact., 68, 594.

WICKerham, L. J., AND BURTON, K. A. 1960. Heterothallism in Saccharomyces rouxii. J. Bact., 80, 492. 